\title{
Treating the whole problem: why therapists need to consider the impacts of financial stress on patients' mental health
}

\begin{abstract}
Numerous research studies have documented the relationship between financial stress and mental health issues. Anxiety, depression, and addiction can all be associated with patient financial stress. Financial issues can be both a cause and an effect of mental health disorders. Treatment can be expensive, and worries about affordability can affect persistence with, and adherence to, a well-designed treatment plan. Therapists, most of whom do not have any type of financial background, may be ill-equipped to assist patients with eliminating the financial issues that may have contributed to their mental health issues, or provide counsel on ways to afford the recommended treatments
\end{abstract}

Keywords: financial stress, mental health treatment, finances
Volume 9 Issue 4 - 2018

\author{
Susan Steffan, Keith Klostermann \\ Department of Counseling \& Clinical Psychology, State \\ University of New York, USA
}

Correspondence: Keith Klostermann, Department of Counseling \& Clinical Psychology, State University of New York, Medaille College, 18 Agassiz Circle, Buffalo, NY 142।4, USA, Email kck35@Medaille.edu

Received: July 25, 2018 | Published: August 16, 2018

\section{Opinion}

Treating the whole problem: why therapists need to consider the impacts of financial stress on patients' mental health

Many American households carry significant amounts of credit card, student loan, and mortgage debt. While unemployment levels are low, under-employment is a real factor for many. MerriamWebster ${ }^{1}$ defines underemployment as the "condition in which people in a labor force are employed at less than full-time or regular jobs or at jobs inadequate with respect to their training or economic needs " (retrieved on 7/5/2018, https://www.merriam-webster.com/dictionary/ underemployment). The pressure to have more and do more is magnified in our social media driven world. Financial pressures exist for most households and may be related to both superficial (e.g., type of car, materialistic wants) as well as survival needs (e.g., food, clothing, shelter). The inability to cope with financial stress may be systemic and can lead to problems within individuals, couples, and families with sleep, anxiety, depression, and addiction, as well as general health malaise and lack of resilience. Illness, in turn, can result in lost productivity, inability to focus on financial strategies, and poor economic choices. These outcomes then put further pressure on household finances, beginning a vicious cycle that can spiral out of control and create serious mental health issues. The relationship between unsecured debt and mental illness is particularly high for substance abuse, suicide, and depression. ${ }^{2}$ Interestingly, when a patient finally seeks treatment, it is often focused on the behavioral issues associated with the diagnosis, which may not address the underlying financial component. Moreover, depending on type of health care coverage (if any), when the cost of treatment is added to the original financial stresses of the household, the patient may experience even greater financial stressors that the new coping mechanisms may not be enough to overcome which may lead to premature treatment dropout. Consequently, clients may lose faith in mental health services and resort to familiar and comfortable unhealthy coping strategies; ultimately, these clients conclude that treatment "didn't work." The consequences of this failure to effectively treat comorbid financial stress and mental health are multiplied when considering that it is not just the identified client being impacted, but also partners and children living in these homes. Thus, the impact of financial stress and related mental health concerns are magnified when considering the impact on the psychosocial development of others living in these homes. Total household debt in the United States has risen for fifteen straight quarters, driven by increasing mortgage and student loan debt (www. newyorkfed.org/newsevents/news/research/2018/rp180517). The average American household carries $\$ 137,063$ in debt (USA Today), yet the U.S. Census Bureau reports that the median household income (2016) in the United States is $\$ 55,322$ (census.gov/topics/incomepoverty/income.html). This mismatch of income and debt levels suggests a legitimate reason for most American households to feel the effects of financial anxiety and stress.

Given the high rate of financial stress in the American population, it would be a reasonable assumption for mental health professionals to expect that some stressors exist with their patients, regardless of perceived income level or stress manifestation. Over $42 \%$ of respondents to a survey of people seeking credit counseling help answered yes to the question "Do you feel your health has been affected by financial problems?". ${ }^{3}$ Assuming that such stressors exist in many patients would suggest that systems need to be set up and made available for all patients to treat the financial issues concurrently with the behavioral issues. By making such treatment "standard" some of the stigma of not having control of one's finances may be alleviated. Since mental health professionals should not be expected to possess the requisite financial skills to effectively counsel their patients, collaboration between behavioral health centers and financial counseling professionals could provide the necessary resources to treat the full spectrum of problems facing patients.

Adjunctive financial counseling could include proven financial coping skills including household budgeting, needs vs. wants definition, credit score management, debt reduction, spending strategies, and employment counseling. In addition, providing experts in mental health insurance coverage can help patients understand the impact of their suggested treatment options on their household finances. This expertise could be offered through embedded 
professionals or an offsite partnership. Given the evidence for the link between mental health issues and financial stress, it is critical that more comprehensive treatments are developed to better address not just stress and anxiety but the underlying causes.

\section{Acknowledgements}

None.

\section{Conflict of interest}

The author declares that there is no conflict of interest.

\section{References}

1. Merriam-Webster. Underemployment. Merriam-Webster: Online Dictionary. 2018.

2. Richardson T, Roberts R. The relationship between personal unsecured debt and mental and physical health: A systematic review and metaanalysis. Clin Psychol Rev. 2005;33(8):1148-1162.

3. O'Neill B, SorhaindoB, Xiao JJ. Negative health effects of financial stress. Consumer Interest Annual. 2005;51:260-262. 